\title{
US set to rejoin international fusion project
}

\section{Geoff Brumfiel, Princeton}

Government officials have indicated that the United States is ready to rejoin ITER, the international project to build an experimental magnetic fusion reactor.

Speaking at celebrations to mark Princeton Plasma Physics Laboratory's fiftieth birthday on 6 June, energy under-secretary Robert Card said that a decision on whether to return to ITER will come "within weeks rather than months".

"We've more or less decided to re-enter talks" with ITER's current participants, says presidential science adviser John Marburger. But, he adds, the United States needs to have a firmer understanding of the project's costs and implications before making a firm financial commitment to it.

The extent of the United States' planned involvement remains an open question, but Marburger says that the country will not offer to pay the $\$ 1$ billion or more needed to host the experimental reactor. "We're not interested in having ITER in the United States," he says. Observers say that US participation would probably involve a commitment of about $\$ 500$ million over 10 years.

The United States and the Soviet Union started ITER, then known as the International Thermonuclear Experimental Reactor, as part of détente in 1988. But just over a decade later, when the engineering phase yielded a design that could have cost up to $\$ 10$ billion to build, Congress instructed the energy department to withdraw from the project. This withdrawal was accompanied by sharp cuts in the domestic fusion budget, leaving US researchers with no prospect of building a large fusion experiment of their own.

Subsequently, the remaining ITER participants - Russia, Canada, Japan and the European Union - have developed a slimmed-down version of the design, which is now expected to cost about $\$ 4$ billion to

\section{Detectors licked by gummy fingers}

\section{David Cyranoski, Tokyo}

Fingerprint-identification equipment can readily be fooled by a piece of gelatin, according to a cursory study undertaken by a Japanese mathematician.

Tsutomu Matsumoto of Yokohama National University says that his findings could undermine the extravagant claims being made for biometry, which uses inherent human traits such as fingerprints to automatically identify individuals.

In Matsumoto's informal study, he made plastic moulds of the subject's fingers, poured gelatin into the moulds, and let the thin 'gummy fingers' harden. Hundreds of trials by 5 people on 11 devices showed that a person wearing the gummy finger could pass for the subject nearly every time, he says.

Even more alarmingly, Matsumoto was able to create an effective fake fingerprint from a piece of glass that the subject had touched. He used a digital camera to photograph an enhanced copy of the mark, etched it on a printed circuit board, and used this to produce a fake finger made of gelatin.

"What's really scary is that anyone could do this," says Matsumoto. "The technology is all on the Internet and can be done cheaply at home."

He emphasizes that he is only dabbling in this research "for fun" while he pursues his real work on the application of cryptography and mathematics to information security.

Spokespeople at Sony and Fujitsu, which make automated fingerprint readers, declined to deny that their devices could be

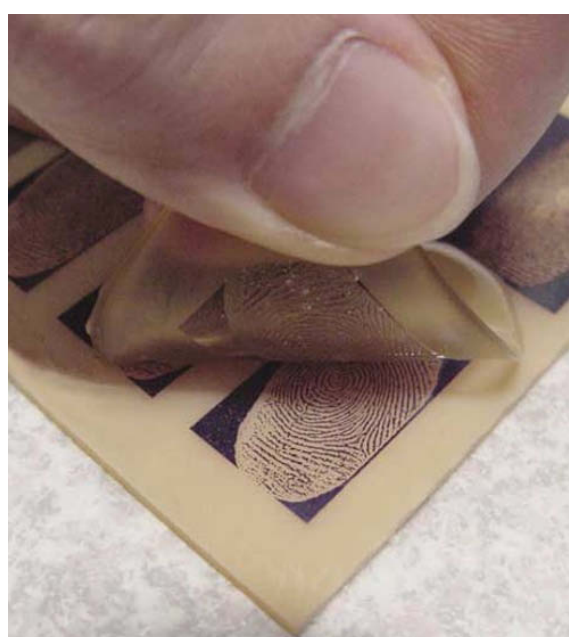

Keep 'em peeled: fake fingerprints can readily be made using gelatin and a simple mould.

deceived by Matsumoto's gummy finger. But Sony and NEC, a third manufacturer, say that they are currently developing better systems. The new NEC reader, for example, will use light from the side that diffuses through the subject's finger, instead of just reflecting off the fingerprint.

Matsumoto is in no doubt that more sophisticated fingerprint-readers could pass his existing test - but he questions the philosophy of relying on biometry for security. "A password can be changed if it gets leaked," says Matsumoto, "but once someone has a copy of your fingerprint or your DNA, they will always be able to use it."

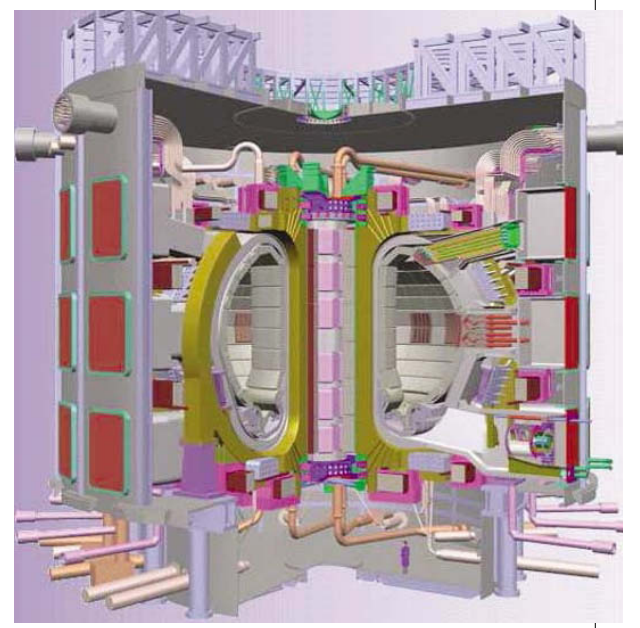

The United States could yet take part in ITER but it has ruled out hosting the reactor itself.

build. At a meeting in Cadarache, France, on 6 June, the project members formally announced four potential sites for the reactor - two in Europe, one in Canada and one in Japan.

In the past year, both members of Congress and the Bush administration have steadily warmed to the idea of once again participating in ITER (see Nature 415, 247-248; 2002)

US researchers reacted with a mixture of caution and optimism to the prospect of the United States rejoining ITER. "I think this is an opportunity for the United States to reengage with the international programme," says Rob Goldston, director of the Princeton Plasma Physics Laboratory in New Jersey. "But I think it is critical that the United States strengthens its domestic programme as part of such an initiative."

The domestic US fusion-research programme "is still pretty fragile", says Gerry Navratil, a physicist at Columbia University. $\mathrm{He}$ is worried that its management will be distracted by negotiations over ITER, and even questions whether US scientists will gain full access to data from the international experiment. He wants the United States to establish a firm withdrawal date should the negotiations prove not to be fruitful, and to continue working on its own, more modest, plasma experiment.

As ITER negotiators begin discussing their choice of site, US researchers will debate the relative merits of ITER and a domestic experiment next month at a conference in Snowmass, Colorado. Goldston hopes that the negotiations abroad and discussion at home will bring the United States closer to the ultimate goal of building a viable fusion reactor. "Between vision and reality a number of steps remain," he says, "but I think it's possible."

www.iter.org 